\title{
Does revascularisation for residual ischaemia in patients with ACS influence prognosis?
}

\author{
Neha Sekhri ${ }^{1}$, Kenneth Fung ${ }^{1 *}$, Mohammed H lqbal ${ }^{2}$, Mohammed O Anwar ${ }^{2}$, Daniel A Jones ${ }^{1}$, Anthony Mathur ${ }^{1}$, \\ Andrew Wragg ${ }^{1}$, Adam Timmis ${ }^{1}$
}

From 19th Annual SCMR Scientific Sessions

Los Angeles, CA, USA. 27-30 January 2016

\section{Background}

Residual myocardial ischaemia early after acute coronary syndromes (ACS) is commonly regarded as an adverse prognostic sign and an indication for revascularisation. However, the benefits of revascularisation for improving prognosis are not known.

\section{Methods}

Analysis of 598 consecutive patients with ACS treated with coronary stenting, all of whom underwent adenosine stress cardiac magnetic resonance (CMR) perfusion imaging to guide revascularisation decisions. Follow-up data were obtained from hospital electronic health records.

\section{Results}

The 598 patients (age $59 \pm 12$ years, 20\% female underwent stress CMR a median of 93 days (IQR: 41, 224 days) after coronary stenting with follow-up for 1.4 years (IQR: 0.6-2.7). Inducible perfusion defects were identified in 294 (49\%) patients of whom 18 (6\%) died during follow-up compared with $6(2.0 \%)$ patients with no perfusion defects $(\mathrm{p}=0.01)$. Of the 294 patients with perfusion defects, $70(24 \%)$ were revascularised (PCI 55, CABG 27) of whom 5 (7\%) died during follow-up compared with $13(6 \%)$ who were not revascularised $(\mathrm{p}=0.68)$. K-M survival analysis confirmed that revascularisation was unassociated with survival benefit, regardless of the severity of ischaemia (Figure 1).

\section{Conclusions}

In our patients with ACS and coronary stenting, inducible ischaemia was associated with increased risk of death during follow-up. Revascularisation did not appear to reduce the risk and should be reserved for improving symptoms in patients on optimal medical therapy.

\section{Authors' details}

'Barts Heart Centre, Barts Health NHS Trust, London, UK. ${ }^{2}$ Barts and the London School of Medicine and Dentistry, London, UK.

Published: 27 January 2016

\section{doi:10.1186/1532-429X-18-S1-059}

Cite this article as: Sekhri et al: Does revascularisation for residual ischaemia in patients with ACS influence prognosis? Journal of Cardiovascular Magnetic Resonance 2016 18(Suppl 1):O59.

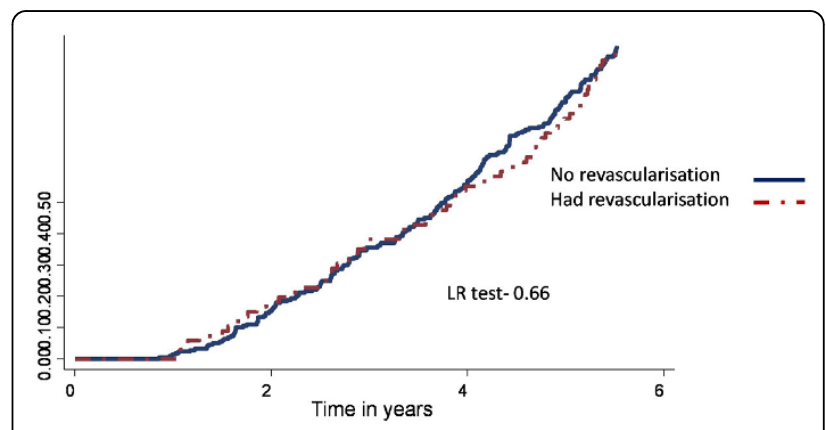

Figure 1 Probability of all cause mortality in patients with perfusion defect stratified by revascularisation.

'Barts Heart Centre, Barts Health NHS Trust, London, UK

Full list of author information is available at the end of the article 